\title{
Assessment of Ossicular Necrosis in Tubotympanic (Mucosal) Type of Chronic Otitis Media
}

\author{
Sakshi Chawla ${ }^{1}$, Amresh Kumar Saxena², Sanjay Kumar ${ }^{3}$ \\ 1, 2, 3 Department of ENT, Subharti Medical College and \\ Chhatrapati Shivaji Subharti Hospital, Meerut, Uttar Pradesh, India.
}

\section{ABSTRACT}

\section{BACKGROUND}

We wanted to study the preoperative clinical, audiological, radiological findings \& compare them with the perioperative findings of ossicular necrosis.

\section{METHODS}

100 patients were clinically diagnosed as mucosal chronic otitis media (COM). They underwent a thorough clinical, audiological \& radiological examination. X-ray mastoid Schuller's view on both sides was done in all patients \& HRCT temporal bone was done in 51 patients. They were then posted for surgery \& findings were compared with the perioperative ossicular necrosis.

\section{RESULTS}

42 patients had ossicular defects perioperatively. Incus was found to be the most commonly necrosed ossicle \& malleus was the most resistant ossicle. There was a positive association found between duration of disease, posterior perforations, large central \& subtotal perforations, polypoidal middle ear mucosa, granulations over margins of perforations \& audiological findings with the perioperative ossicular defects. HRCT was the most reliable investigation to predict ossicular necrosis.

\section{CONCLUSIONS}

From the study, it was concluded that all patients with mucosal COM can be assessed preoperatively for ossicular erosion. HRCT gives us a preoperative picture of the extent of ossicular necrosis \& helps the surgeon in planning the surgical intervention.
Corresponding Author: Dr. Sakshi Chawla, A-1/164 Safdarjung Enclave New Delhi-110029, Delhi, India. E-mail: sakshich@gmail.com

DOI: $10.14260 /$ jemds/2021/637

How to Cite This Article:

Chawla S, Saxena AK, Kumar S. Assessment of ossicular necrosis in tubotympanic (mucosal) type of chronic otitis media. J Evolution Med Dent Sci 2021;10(36): 3127-3131 DOI:

10.14260/jemds/2021/637

Submission 25-03-2021,

Peer Review 29-05-2021,

Acceptance 05-06-2021,

Published 06-09-2021.

Copyright (C) 2021 Sakshi Chawla et al This is an open access article distributed under Creative Commons Attribution License [Attribution 4.0 International (CC $B Y 4.0)]$

\section{KEY WORDS}

COM, HRCT, Ossicular Necrosis, Mucosal, PTA 


\section{BACKGROUND}

Chronic otitis media (COM) refers to a chronic infection of the mucosa lining the middle ear cleft, which includes the middle ear, attic, aditus, antrum, mastoid air cells and Eustachian tube. ${ }^{1}$

COM is an inflammatory process in the middle ear space that results in the long term, or more often, permanent changes in the tympanic membrane including atelectasis, dimer (formerly "monomer") formation, perforation, tympanosclerosis, retraction pocket development, or cholesteatoma. There is variable involvement of the ossicular chain. COM results from long-term Eustachian tube dysfunction with a poorly aerated middle ear space, multiple bouts of acute otitis media, persistent middle ear infection, or other chronic inflammatory stimuli. ${ }^{2}$

\section{Com Has Been Broadly Classified into Two Types}

Tubotympanic disease (safe or benign) and atticoantral disease (Unsafe or dangerous). ${ }^{1}$ Tubotympanic type involves the anteroinferior part of the middle ear cleft i.e. Eustachian tube, mesotympanum and is associated with central perforation. Atticoantral type involves posterosuperior part of the cleft, i.e. attic, aditus, antrum \& mastoid and is associated with an attic or a marginal perforation. The disease is often associated with the bone eroding process \& the formation of cholesteatoma, granulations or osteitis. A new classification of COM: Mucosal chronic otitis media (Active \& Inactive Stage) or Squamosal otitis media (Active \& Inactive Stage). Chronic otitis media can be classified as active, inactive, \& inactive with frequent reactivation. The classification scheme followed here was developed by Nadol. ${ }^{3}$

COM-TTD (Mucosal) is characterized by chronic inflammation of the middle ear and mastoid mucosa. Active mucosal CSOM is often associated with the resorption of parts or all of the ossicular chain (Resorptive osteitis). ${ }^{4}$ Resorption of bone is a feature of active mucosal and active squamosal epithelial COM. The ossicles, thus affected, typically show hyperaemia with the proliferation of capillaries and prominent histiocytes. ${ }^{5}$

\section{Objectives}

- To study the preoperative clinical findings \& audiological assessment and compare it with the perioperative findings of ossicular necrosis.

- To correlate radiological findings for ossicular necrosis in the pneumatized or sclerosed mastoid.

- Correlation of high-resolution computed tomography (HRCT) temporal bone findings with the peroperative ossicular necrosis.

\section{METHODS}

100 patients, of age group 10 to 50 years and both sexes, who were clinically diagnosed as mucosal chronic otitis media, scheduled to undergo myringoplasty or tympanoplasty, patients with unilateral disease and consenting for the study were included in our study. Patients with bilateral chronic otitis media, patients with squamosal disease or marginal perforations, patients with a history of previous ear surgery or trauma (on the same side) were excluded from the study. They were subjected to a detailed history, general physical examination, and ENT examination. Tuning fork test \& audiometry were done. X-ray mastoid Schuller's view on both sides was done in all patients \& HRCT temporal bone was done in 51 patients. Patients were then posted for surgery \& perioperative findings were noted. Correlation of the preoperative clinical, audiological, and radiological findings was done with the preoperative findings of ossicular necrosis. It was an observational prospective study done from $1^{\text {st }}$ November 2014 to $31^{\text {st }}$ July 2016 (21 months).

\section{Statistical Analysis}

Statistical analysis was done wherever applicable and possible based on the chi-square test and p-value. Statistically significant findings in the study were established as results.

\section{RESULTS}

After analysing the subjects in terms of history, general physical and specific otologic examination, they were then subjected to audiological examination, that is, a pure tone audiogram was done in all the patients as the preoperative hearing assessment. Also, all the patients underwent radiological assessment in the form of X-ray mastoid bilateral Schuller's view. Out of the total 100 patients, 51 patients underwent an HRCT scan of the temporal bone. After a thorough preoperative evaluation of the patients, all the patients underwent surgery and the ossicular status of the patients was analysed.

The trend of the duration of disease was found to be statistically significant. (Chi-square test $=17.18, \mathrm{P}=0.0006$ ). There was maximum ossicular necrosis in patients in whom the duration of the disease was more than 10 years -28 out of 32 patients showed ossicular necrosis (88\%) and this association was statistically significant $(\mathrm{P}=0.0001)$. Also when the duration of the disease was less than 1 year, the least number of patients showed necrosis of the ossicles only 3 out of 30 patients (10\%) showed ossicular necrosis. Even this association was statistically significant $(\mathrm{P}=0.003)$. When the duration of the disease was from 1 to 5 years then ossicular necrosis occurred in $21 \%$ of patients and when the duration of the disease was 5-10 years, the perioperative necrosis of ossicles was seen in $43 \%$ of patients. But these findings were not statistically significant.

Individually, it was found that the maximum ossicles were found to be eroded in posterior + inferior perforations i.e. 63 $\%$, followed by posterior perforations in which $33 \%$ patients had ossicular necrosis. Anterior + inferior perforations showed $5 \%$ of patients with ossicular necrosis and none of the patients with anterior perforations showed perioperative ossicular necrosis. Overall our study assessed that the total number of patients with anterior perforations (anterior \& anterior + inferior) were $33(33 \%)$ and the total number of posterior perforations (posterior \& posterior + inferior) were of 50 patients ( $50 \%$ ). Conclusively, 27 out of 50 patients with 
posterior perforations had ossicular necrosis (i.e. $54 \%$ ). And 1 out of 33 patients with anterior perforations had perioperative ossicular necrosis (i.e., $3 \%$ ).

\begin{tabular}{|cccc|}
\hline $\begin{array}{c}\text { Size of the Central } \\
\text { Perforation }\end{array}$ & $\begin{array}{c}\text { No. of } \\
\text { Patients }\end{array}$ & $\begin{array}{c}\text { Necrosed Ossicles Seen } \\
\text { Perioperatively }\end{array}$ & Percentage \\
Small & 10 & 1 & 10 \\
Moderate & 22 & 4 & 18.2 \\
Large & 54 & 23 & 42.6 \\
Subtotal & 14 & 14 & 100 \\
Total & 100 & 42 & \\
\hline Table I. The Size of Perforation \& the Perioperative Ossicular Findings \\
\hline
\end{tabular}

\begin{tabular}{|cccc|}
\hline $\begin{array}{c}\text { Middle Ear Mucosa } \\
\text { Findings }\end{array}$ & No. of Patients & $\begin{array}{c}\text { Perioperative Ossicular Status } \\
\text { Necrosed Ossicles }\end{array}$ & $\begin{array}{c}\text { Percentage } \\
\text { Normal }\end{array}$ \\
Congested & 53 & 1 & 2 \\
Oedematous & 17 & 6 & 75 \\
Polypoidal & 22 & 14 & 82 \\
Total & 100 & 21 & 96 \\
\hline Table II. Middle Ear Mucosa Findings \& the Perioperative Ossicular \\
Necrosis \\
\hline
\end{tabular}

\begin{tabular}{|cccc|}
\hline PTA Findings (in DB) & Total & $\begin{array}{c}\text { Perioperative } \\
\text { Ossicular Necrosis }\end{array}$ & Percentage \\
Mild (26-40) & 47 & 0 & 0 \\
Moderate (41-55) & 35 & 24 & 69 \\
Moderately severe (56-70) & 18 & 18 & 100 \\
Severe (71-90) & 0 & 0 & 0 \\
Profound (91+) & 0 & 0 & 0 \\
Total & 100 & 42 & \\
\hline Table III. Audiological Findings (Pure Tone Audiometry-PTA) \& the \\
Perioperative Findings of Ossicular Necrosis \\
\hline
\end{tabular}

\begin{tabular}{|c|c|c|c|}
\hline $\begin{array}{l}\text { X-Ray Mastoid Schuller's } \\
\text { View Both Sides }\end{array}$ & $\begin{array}{c}\text { No. of } \\
\text { Patients }\end{array}$ & $\begin{array}{l}\text { Perioperative Ossict } \\
\text { (Necrosed Ossicles) }\end{array}$ & $\begin{array}{l}\text { ular Status } \\
\text { Percentage }\end{array}$ \\
\hline Bilateral pneumatized mastoid & 29 & 2 & 7 \\
\hline Unilateral sclerosed mastoid & 44 & 35 & 80 \\
\hline \multicolumn{4}{|c|}{$\begin{array}{l}\text { Table IV. Pneumatization of Mastoid (As Seen in X-ray Mastoid } \\
\text { Schuller's View) \& the Perioperative Ossicular Necrosis }\end{array}$} \\
\hline
\end{tabular}

\begin{tabular}{|cccccccccc|}
\hline & & & & & \\
Ossicular destruction- \\
$\begin{array}{c}\text { Malleus handle (tip) } \\
\text { Malleus head }\end{array}$ & 2 & 3 & 0 & 1 & 66.67 & 100 & 0.98 \\
$\begin{array}{c}\text { Incus lenticular } \\
\text { process }\end{array}$ & 13 & 14 & 0 & 1 & 92.86 & 100 & 0.98 \\
$\begin{array}{c}\text { Incus long process } \\
\text { Body of incus }\end{array}$ & 8 & 7 & 1 & 0 & 100 & 97.73 & 0.98 \\
$\begin{array}{c}\text { Incus + stapes } \\
\text { suprastructure (head } \\
\text { of stapes) }\end{array}$ & 5 & 0 & 0 & 0 & 0 & 0 & 0 \\
\hline Table V. Correlation of HRCT Temporal Bone Findings with \\
Perioperative Ossicular Necrosis
\end{tabular}

\section{DISCUSSION}

In our study in COM (TTD or mucosal), the age group ranged from 11 to 50 years with a mean age of 25.01 years, which is similar to the study done by Nayak GK et al. ${ }^{6}$ i.e. 23.17 years \& lower as compared to Haidar et al. who claimed mean age as 33.4 years. Also in our study, the maximum number of patients was 41 lying within the age group of 21-30 years. And a minimum number of patients i.e. 5 patients were in the age range of 41-50 years. The youngest patient was 11 years old and the oldest patient was 50 years old. In our study, COM (mucosal) showed male preponderance with a male to female ratio of 1.2:1. This is also in accordance with the study done by Sade et al. ${ }^{7}$ who reported that the incidence was 1.4 times higher in men as compared to women. In the study done by
Jose et al. ${ }^{8}$ males predominated $(64.7 \%)$ compared to females (35.3\%). In contrast, Jayakumar et al. ${ }^{9}$ who studied preoperative indicators for ossicular necrosis in COM (TTD) had female preponderance. Hence, the disease was seen more commonly in the left ear (54\%) as compared to the right ear (46\%). In our study, this was a new positive finding for COM (TTD) as no study had been done previously to show these results.

In our study, around $91 \%$ of the population belonged to the low socioeconomic status suggesting that the lack of hygiene, poor nutritional status \& reduced resistance to infection were probable causative factors.

Tuli et al. ${ }^{10}$ reported that the prevalence of deafness in rural areas is almost double than that is observed in urban areas, consequent upon the low level of literacy \& lack of health consciousness, along with contributing factors like malnutrition and swimming in dirty ponds. Jung T. K et al. ${ }^{11}$ revealed that low socioeconomic status and repeated exposure of many children were the most important sociodemographic risk factors.

In our study, the most common complaint was discharge from the ear which was present in all the patients $100 \%$. This is in accordance with Sade et al. ${ }^{7}$ who found that discharge was the first symptom in $62.0 \%$ of cases and hyperacusis was present in $11.0 \%$ of cases. In mucosal COM, on examination of the tympanic membrane, the patients having various sites of perforations were as follows. Overall, in our study, the number of posterior perforations was more, which is, $50 \%$ in comparison to anterior perforations that is, $33 \%$. This is in contrast to a previous dictum that mucosal COM is a disease of the anteroinferior part of the middle ear. On examination of the tympanic membrane, the site of the perforation was found to be posterior in a maximum number of patients $50 \%$ as compared to anterior perforations of 33 $\%$ of patients. The rest of the patients showed perforations involving all the quadrants $14 \%$ \& inferior perforations $3 \%$. In our study, the maximum number of patients had large central perforation seen in $54 \%$ of patients and the least common size of perforation was small central perforation 10 $\%$. Granulations over the margins of the perforation were seen in $8 \%$ of the patients, more commonly over the posterior margins as compared to the anterior margins. Examination of the middle ear mucosa showed a normal mucosa in the maximum number of patients i.e. $53 \%$. The rest $47 \%$ of patients showed diseased mucosa. Polypoidal type of middle ear mucosa was seen in $22 \%$ of patients and oedematous mucosa was seen in $17 \%$ of patients and $8 \%$ of patients showed congested mucosa. Mild hearing loss was seen in maximum patients i.e. 47 patients (47 \%) followed by moderate hearing loss, which was seen in 35 patients (35\%), moderately severe hearing loss was seen in 18 patients (18 $\%)$.

X-ray mastoid Schuller's view showed $29 \%$ of the involved mastoid cells to be sclerotic and $44 \%$ to be pneumatized. The rest $27 \%$ of the patients had bilaterally sclerosed mastoid which was a normal finding in $20 \%$ of the population. In our study, HRCT temporal bone was done in 51 patients and normal HRCT was seen in 23 patients (45.09\%). HRCT temporal bone showing ossicular destruction was seen in 28 patients $(54.9 \%)$. The incus was the most common eroded ossicle where the lenticular process was the most common part to be necrosed (26\%) followed by the long 
process (16\%). Combined incus \& stapes suprastructure was found to be eroded in $10 \%$ of patients. The tip of the handle of the malleus was the least common ossicle (4\%) for ossicular erosion based on HRCT temporal bone. Surgery was performed on all patients and normal ossicles were found in $58 \%$ of patients. Out of $42 \%$ of the patients with necrosed ossicles, incus was the most common ossicle to be necrosed (29\%), combined incus and head of stapes erosion were seen in $9 \%$ of patients. Malleus was the most resistant ossicle for erosion in $3 \%$. The lenticular process of the incus was the most common part (69\%) of incus which was susceptible to necrosis, followed by the long process (28\%). These findings were in accordance with the study done by Austin. ${ }^{12}$ The trend of the duration of disease was found to be statistically significant. In our study, the number of patients having ossicular necrosis seen in posterior perforations was more as compared to the anterior perforations. Incus erosion was found to be more frequent in the overall posterior site of perforation, which was statistically significant. In our study, as the size of the perforation increased, the chances of ossicular necrosis also increased and this trend was statistically significant.

Individually, large central perforation \& subtotal perforations were statistically significant with the findings of perioperative ossicular necrosis. Out of the 10 patients having small central perforations, 1 patient had ossicular necrosis, the lenticular process of incus was eroded. This shows that even in small central perforations, there are chances of ossicular erosion. This grading system was done according to Griffin's classification- (Griffin WL et al.) where Grade I perforation (perforation smaller than $25 \%$ of the tympanic membrane involvement), Grade II perforation (perforation of $25-50 \%$ of the pars tensa involvement), Grade III perforation (involving 50-75 \% of the tympanic membrane pars tensa) \& Grade IV perforation (involving $>75$ $\%$ of the pars tensa).

In our study, it was observed that granulations over the perforation margins, polypoidal \& oedematous middle ear mucosa were found to be highly significant with perioperative ossicular necrosis. Many studies done by Jeng Fuh-Cherng et al. ${ }^{13}$ Schachern et al. ${ }^{14}$ Chole and Choo et al. ${ }^{15}$ \& Ruby et al. ${ }^{16}$ have also concluded that the presence of granulation tissues is significantly associated with erosion of ossicles in tubotympanic CSOM. In our study, there is also a significant trend in the audiological findings \& the findings of ossicular necrosis. A statistically significant association was seen between moderate hearing loss \& moderately severe hearing loss and the perioperative ossicular necrosis. Hence, the greater the degree of hearing loss, the more the chances of ossicular necrosis. Patients having unilateral sclerosis of the mastoid showed more cases of ossicular necrosis (80\%) preoperatively and the patients with pneumatized mastoid bone had only $80 \%$ of the patients with unilateral sclerosed mastoid and only $7 \%$ patients with pneumatized mastoid showed perioperative ossicular necrosis. HRCT was found to be the most reliable investigation to predict ossicular necrosis. The accuracy rate to predict the necrosis of incus lenticular process, long process \& malleus handle was $0.98 \%$.

\section{CONCLUSIONS}

- The lenticular process of the incus was the most common part (69\%) of incus which was susceptible to necrosis followed by the long process (28\%).

- The trend of the duration of disease was found to be statistically significant.

- The number of patients having ossicular necrosis seen in posterior perforations was more as compared to the anterior perforations.

- Large central perforations and subtotal perforations were statistically significant with the findings of perioperative ossicular necrosis.

- Granulations over the perforation margins, polypoidal and oedematous middle ear mucosa were found to be highly significant with perioperative ossicular necrosis.

- A significant association was seen between moderate hearing loss and moderately severe hearing loss and perioperative ossicular necrosis.

- HRCT temporal bone gave accuracy rates of $0.98 \%$ in detecting the erosion of the lenticular process \& the long process of the incus \& the malleus handle.

Data sharing statement provided by the authors is available with the full text of this article at jemds.com.

Financial or other competing interests: None.

Disclosure forms provided by the authors are available with the full text of this article at jemds.com.

\section{REFERENCES}

[1] Seiden AM, Tami TA, Penssak ML, et al Otorhinolaryngology, the essentials. New York, NY: Thieme 2002: p. 44-58.

[2] Gulya AJ, Minor L, Poe D. Pathology and clinical course of inflammatory disease of the middle ear. In: Glasscock, Shambaugh edr. Surgery of the ear. $6^{\text {th }}$ edn. Shelton, Ct, USA: People's Medical Publishing House 2010: p. 427-8.

[3] Nadol JB. The chronic draining ear. In: Gates GA, edr. Current therapy in otolaryngology - head and neck surgery. Philadelphia: Decker 1987: p. 18-22.

[4] Schuknecht HF. Pathology of the ear. 2nd edn. Philadelphia: Lea and Febiger 1993: p. 191-253.

[5] Thomsen J, Jorgensen MB, Bretlan P, et al. Bone resorption in chronic otitis media. A histological and ultrastructural study. I. Osicular necrosis. J laryngol Otol 1974;88(10):975-81.

[6] Nayak GK, Barhma D, Chatterjee P, et al. Ossicular chain status in chronic suppurative otitis media. IOSR Journal of Dental and Medical Sciences 2016;3:20-3.

[7] Sadé J, et al. Ossicular damage in chronic middle ear inflammation. Acta Otolaryngol 1981;92:273-83.

[8] de Aquinol JEAP, Filho 2nd NAC, de Aquino JNP 3rd. Epidemiology of middle ear and mastoid cholesteatomas: study of 1146 cases. Braz J Otorhinolaryngol 2011;77(3):341-7.

[9] Jayakumar CL, Inbaraj LR, Pinto GJO. Pre-operative indicators of ossicular necrosis in tubotympanic CSOM. Indian Journal of Otolaryngology and Head and Neck Surgery 2016;68(4):462-7. 
[10] Tuli BS, Pharmar TL, Kumar S. Incidence of deafness in school going children in Patiala. Indian $\mathrm{J}$ Otol 1988; $40: 137-8$

[11] Jung TT, Hanson JB. Classification of otitis media and surgical principles. Otolaryngologic clinics of North America 1999;32(3):369-83.

[12] Austin DF. Ossicular reconstruction. Arch Otolaryngol 1971;94(6):525-35.

[13] Jeng FC, Tsai MH, Brown CJ. Relationship of preoperative findings and ossicular discontinuity in chronic otitis media. Otology and Neurotology 2003;24(1):29-32.
[14] Schachern P, Paperella MM, Sano S, et al. A histopathological study of the relationship between otitis media and mastoiditis. Laryngoscope 1991;101(10):1050-5.

[15] Chole RA, Choo MJ. Chronic otitis media, mastoiditis and petrositis. In: Cummings CW, edr. Otolaryngology head neck surgery. $3^{\text {rd }}$ edn. St. Louis: CV Mosby 1998;4:302646.

[16] Albert RRA, Job A, Kuruvilla G, et al. Outcome of bacterial culture from mastoid granulations: is it relevant in chronic ear disease? Journal of Laryngology Otology 2005;119(10):774-8. 